\title{
Family structure and its impacts on the restrictions of self-perception of elderly health levels in Brazil
}

\author{
Estrutura familiar e seus impactos sobre as restrições \\ da autopercepção dos níveis de saúde dos idosos no Brasil
}

Mércia Santos da Cruz ${ }^{1}$

Jair Andrade Araujo ${ }^{2}$

Adriano Nascimento da Paixão ${ }^{1}$
${ }^{1}$ Universidade Federal da Paraíba. Cidade Universitária, Castelo Branco. 58059-900 João Pessoa PB Brasil. mercia_sc@hotmail.com

${ }^{2}$ Centro de Ciências Agrárias, Universidade Federal do Ceará. Fortaleza CE Brasil.

\begin{abstract}
The aim of the article is to investigate the impacts of co-residence over spouce and $\backslash$ or children on self-perceived health among Brazilian elderly. The database used was the health supplement of the National Sample Survey of Households (PNAD) conducted by the Brazilian Institute of Geography and Statistics (IBGE) in 2008. The sample consists of 36551 people from all regions of the country such as urban areas and rurals. The results indicate that seniors with better socioeconomic status, who don't have physical mobility problems are more propenspos to a better self report among their health, regardless of the gender of the elderly. Regarding the impact of co-residence family health of respondents, living with daughters increases the probability that perception is better (specifically good or very good). Moreover,the results are consistent with the hypothesis that elderly brazilians realize better their health with home living with daughters and/or spouse.
\end{abstract}

Key words Elderly, Self-perception, Ordered logit
Resumo Este artigo tem como objetivo investigar os impactos da corresidência de cônjuge e/ou filhos sobre a autopercepção de saúde dos idosos brasileiros. A base de dados utilizada foi o suplemento de saúde da Pesquisa Nacional por Amostra de Domicílio (PNAD) realizada pelo Instituto Brasileiro de Geografia e Estatística (IBGE) no ano de 2008. A amostra é composta de 36.551 pessoas de todas as regiões do país de áreas urbanas e rurais. Os resultados indicam que os idosos com melhor status socioeconômico e sem problemas de mobilidade física são mais propenspos a um melhor autorreporte de sua saúde, independente do gênero. Quanto ao impacto da corresidência familiar na saúde dos pesquisados, a convivência com filhas aumenta a probabilidade que a percepção seja melhor (especificamente boa ou muito boa). Ademais, os resultados são compatíveis com a hipótese de que os idosos brasileiros percebem melhor sua saúde com a convivência domiciliar com filhas e/ ou cônjuge.

Palavras-chave Idosos, Auto-percepção, Logit ordenado 


\section{Introduction}

When analyzing the profile of the elderly in the 2000s, it is emphasized that the number of individuals over 60 years old has grown in the country and that the estimates for 2020 indicates that the elderly population will be of 30 million people with a stake $13 \%$ of the total population, among the facts that corroborates such statements are the modifications on fertility rate and the longevity of the population observed since the $1960 \mathrm{~s}^{1}$.

According to the IBGE census of $2010^{2}$, the elderly population over 65 years old is approximately 14 million people. It is noteworthy that the reduction of fertility levels caused a decrease of $42.7 \%$ (1960) to $24.1 \%$ (2010) of the share of population between 0 and 14 years old. Moreover, the mortality reduction caused an increase of $54.6 \%$ to $68.5 \%$, the share of working age population (15-64 years old). And yet, the increase in the share of the population of 65 years old or more in the total Brazilian population, in the period $1960 / 2010$, rose from $2.7 \%$ to $7.4 \%$.

It is known that with aging, there are changes in the social, psychological and physiological in the lives of individuals and with decreasing functional activity of the organism. The functional losses can be seen mostly in the systems cardio respiratory, cardiovascular, immunologic and sensorial, among others. Therefore, it is understood that the elderly needs medical care and/or family members (spouses and children) to improve their life quality.

Undoubtedly, an elderly person needs attention, both as family as doctors and public and/or private health system. As about $30 \%$ of the population over 65 years of age suffers falls one or more time each year, and approximately $8 \%$ to $17 \%$ of the elderly falls several times annually ${ }^{3}$. These falls characterizes a public health problem, because they are the leading cause of unintentional injury and death. About $70 \%$ of these events cause fractures, most commonly in the hip, and this entails functional mobility problems. In a way, it is assumed that living with family members avoids these situations and would help in reducing the mortality rate.

According to Glaser and Grundy ${ }^{4}$, several studies have shown that there is a relationship between marital status and morbidity of individuals, and older married people generally reports lower morbidity than their unmarried counterparts. It also corroborates the same ideas ${ }^{5,6}$. Already Kaplan et al. ${ }^{7}$ argue that the impact of marital status on health and self-reported limitations in activities of daily life was insignificant in a British study, while the presence of children reduces mortality for women and older men, but to a greater extent for women.

Several studies have attempted to the impact of family members on mortality in old age in developed countries ${ }^{8,9}$. Unlike the situation in other countries, it is unclear the impact of kinship ties on morbidity, mortality or health levels of the elderly in Brazil.

For example, Rahman ${ }^{8}$ related the impacts of family structure, spouses residence and children with mortality rate in rural Bangladesh with emphasis on age and gender differences. It was used a sample of 9.365 individuals aged over 60 years old and concludes that the presence of the head of family, especially wives and children have impact in reducing mortality of men and women in rural Bangladesh with variable effects between gender and age.

In the same perspective ${ }^{9}$, it uses information in rural Bangladesh to demonstrate that the spouses and children have great impact on mortality of elderly people, with significant differences by sex of the elderly and the age of child. Also finds that the spouse's presence in the house helps to significantly reduce mortality by similar magnitudes for both man and woman elderly. On the other hand, co-residents adult sons also decrease mortality for older women much more than for older men. Furthermore, independently of their civil status women seems to benefit more co-residents adult sons. Finally, the analysis suggests that the impact of spouses and children on mortality in old age is not substantially measured by changes in the elderly economic status.

As Corrêa et al. ${ }^{10}$ investigated how the size and structure of the social network of the elderly influence the attention it devoted by each individual of your network. Therefore, they built two indexes of take care of the elderly from the Health Survey data, Welfare and Aging in Latin America and the Caribbean (Sabe) to the city of São Paulo in 2000 and they applied ordered logistic regression models. They considered that the attention given to the elderly requires time and communication and that its support network encompasses both co-residents as his sons and brothers non-co-residents and other non-co-residents people who have some relationship with the elderly.

According to Corrêa et al..$^{10}$ the attention and time devoted to the elderly, as well as related to the characteristics of the people involved, the 
structure and size of the network, are also associated with the structure, size and characteristics of the social networks of these people. Results suggested how the composition of the social network influences individual decisions, showing the importance of knowledge of social networks and the decisions made in the family environment for public policy.

The study ${ }^{11}$ contributes to the understanding of social relations and the assessment of the health of older people in the Western Pacific, thus it investigates whether the social integration influences the way how older people assess their health. Based on information from four countries (Malaysia, Philippines and South Korea) showed that elderly social relations and social integration are related to health assessments in all countries between 1980-1990.

Therefore, the article starts from the assumption that the absence of spouse and children can influence the self-perception of health levels and the survival of older people. Another objective is to test how the main determinants of self-perceived health status of the elderly in Brazil, knowing that it is a country with growing elderly population.

In Brazil ${ }^{12}$, it makes a descriptive analysis of the self-assessment health with database from IBGE in 1998, 2003 and 2008. The results suggested an improvement in self-perception of health of the elderly in the period studied.

Moreover, it is necessary to study that age group. The following question arises: what are the determinants of health self-perception status of the elderly in Brazil? It seeks to answer this question by analyzing health self-perception status of the elderly. Note that this issue was not addressed in previous researches and comes to be of utmost importance when considering that the elderly population represents about $7 \%$ of the Brazilian population.

In other words, the article's aim was to investigate the impacts of residents spouses and children over self-perceived health of men and women aged over 60 years in Brazil. Its intended to innovate on the discussion about health of older people when considering the impact of spouses and children over the health of older people.

Following, in addition to this introduction, this paper presents five more sections. The second hosts and discusses the construction of database and the econometric model; the fourth presents the results; the fifth the results are discussed and in the last section, the closing remarks followed as usual by the bibliographies.

\section{Materials and Methods}

To achieve this goal, it was used an ordered logit model with dependent variables on which measures the levels of self-declaration of elderly status and the conditioning variables will be: age, household income, years of education, residence macro-regions, if he has health plan, if he lives in an urban or rural area, if he has physical mobility and mobility caused by diagnosed illnesses, family composition within the household. Those variables were built from National Household Sample Survey (PNAD)' Health Supplement carried out by the Brazilian Institute of Geography and Statistics (IBGE) in 2008. This database is the latest that deals with health within the PNAD microdata. The National Household Sample Survey has been chosen because it is the only database that includes the set of covariates to achieve the proposed goals and it covers the entire national territory. National Health Survey (PNS, 2013) was carried out by the Brazilian Institute of $\mathrm{Ge}$ ography and Statistics (IBGE) in 2013, a more current database that also deals with issues of elderly's health, however, the release has not yet been fully completed.

\section{Source and data processing}

In order to meet the objective of measuring the impact of co-residence of children and spouses in health self-perception of seniors, it was used as an identifier of self-assessment of their own health the interviewed answer to the following question: "In general, do you consider your own health as ?"; having as possible answers: 1) Very good, 2) Good, 3) Regular, 4) and Bad 5) Very bad. The information was collected at the health supplement database (PNAD, 2008) ${ }^{13}$ and becomes the model's dependent variable.

To analyze the determinants of health self-perception of the elderly in Brazil it will be used the following independent variables: age, household income range, education, residence macro-region, if has health insurance, if lives in an urban or rural area, if has physical mobility and/or mobility affected by undiagnosed diseases. Regarding family composition within the household, it will be considered seven groups, namely: residing only with daughters, living only with children, living with spouse sons and daughters, do not have spouse and living only with children and residing only with spouse, without children.

Chart 1 summarizes the set of controls discussed and used in this research. 
Chart 1. Description of explainable variables used on family composition impact over the Brasilian elderly health self-report.

\begin{tabular}{|c|c|c|}
\hline Dimentions & Derivated Variables & Indicators \\
\hline \multirow[t]{7}{*}{$\begin{array}{l}\text { Familiar } \\
\text { Composition }\end{array}$} & Psons & $X_{i, 1}^{1}=\left\{\begin{array}{c}1, \text { lives only with sons } \\
0, \text { if not }\end{array}\right.$ \\
\hline & Pdaughters & $X_{i, 1}^{2}=\left\{\begin{array}{c}1, \text { lives only with daughters } \\
0, \text { if not }\end{array}\right.$ \\
\hline & Pcff & $X_{i, 1}^{3}=\left\{\begin{array}{c}1, \text { lives with spouses and children } \\
0, \text { if not }\end{array}\right.$ \\
\hline & Conjsons & $X_{i, 1}^{3}=\left\{\begin{array}{c}1, \text { lives with spouses and son } \\
0, \text { if not }\end{array}\right.$ \\
\hline & Conjdaughters & $X_{i, 1}^{3}=\left\{\begin{array}{c}1, \text { lives with spouses and daughter } \\
0, \text { if not }\end{array}\right.$ \\
\hline & Npcmff & $X_{i, 1}^{3}=\left\{\begin{array}{c}1, \text { doesn't have spouses and lives with children } \\
0, \text { if not }\end{array}\right.$ \\
\hline & Psc & $X_{i, 1}^{3}=\left\{\begin{array}{c}1, \text { only lives with spouses and have no children } \\
0, \text { if not }\end{array}\right.$ \\
\hline \multirow[t]{2}{*}{ Socioeconomics } & Studying years & $X_{i, 2}^{1}=\{0$ to 16 years \\
\hline & Family income & $X_{i, 2}^{2}=\{0$ to 7 levels \\
\hline \multirow[t]{2}{*}{ Demographics } & Age & $X_{i, 3}^{1}=\{$ Years of age \\
\hline & $\begin{array}{l}\text { No of persons by } \\
\text { room }\end{array}$ & $X_{i, 3}^{2}=\left\{\begin{array}{l}1, \text { if }<3 \\
0, \text { if not }\end{array}\right.$ \\
\hline \multirow[t]{3}{*}{ Health } & Fisical Mobility & $X_{i, 4}^{1}=\left\{\begin{array}{c}1, \text { if has dificulty in moving and or doing tasks and or feeding } \\
0, \text { if not }\end{array}\right.$ \\
\hline & Decease mobility & $X_{i, 4}^{2}=\left\{\begin{array}{l}1, \text { if not } \\
0, \text { if yes }\end{array}\right.$ \\
\hline & Health plan & $X_{i, 4}^{3}=\left\{\begin{array}{l}1, \text { if yes } \\
0, \text { if not }\end{array}\right.$ \\
\hline \multirow[t]{5}{*}{ Regions } & North & $X_{i, 5}^{1}=\left\{\begin{array}{c}1, \text { if resides on North } \\
0, \text { if not }\end{array}\right.$ \\
\hline & Northeast & $X_{i, 5}^{2}=\left\{\begin{array}{c}1, \text { if resides on Northeast } \\
0, \text { if not }\end{array}\right.$ \\
\hline & South & $X_{i, 5}^{3}=\left\{\begin{array}{c}1, \text { if resides on South } \\
0, \text { if not }\end{array}\right.$ \\
\hline & Southeast & $X_{i, 5}^{4}=\left\{\begin{array}{c}1, \text { if resides on Southeast } \\
0, \text { if not }\end{array}\right.$ \\
\hline & Midwest & $X_{i, 5}^{5}=\left\{\begin{array}{c}1, \text { if resides on Midwest } \\
0, \text { if not }\end{array}\right.$ \\
\hline
\end{tabular}

Source: Self elaboration after PNAD 2008 data.

Based on the information presented above, which was marked by the description the variables, as well as its sources and treatment, the next step in the research is to present some descriptive characteristics of the sample, reported in Tables 1 and 2. Table 1 shows the frequency distribution and the relative frequency percentage of the elderly health status. Table 2 will show the descriptive statistics of the explanatory vari- ables of the impact of family composition on self-reported health among Brazilian elderly.

It should be noted that PNAD is a complex type of research and, therefore, it will be required to complete the sample design that includes such a feature of the database. All statistics presented in this paper (descriptive analysis and econometric models) considers the sampling design, which in turn allows the results can be extrapolated to the population ${ }^{13}$. 


\section{Estimation strategy: ordered logit model}

The response variable investigated in this research beyond the discreet character already mentioned, also has a sorting feature (given by the five different levels of health perception already mentioned), so the econometric model used as a tool for obtaining the study estimations will be a logit model considering the ordinal nature of the dependent variable that may assume " $n$ " different categories ${ }^{14,15}$. The discrete nature of the model's dependent variable, named by the five different levels of self-declaration of health status are: 1-very good, 2-good, 3-regular, 4-bad, and 5-very bad.

Equation (1) shows the structure of ordinal model which can be defined as follows:

$$
y^{*}=X^{\prime} \beta+u
$$

In the model expressed in equation (1), the dependent variable and $y^{*}$ is subdivided into $J$ different categories, it has:

$$
y=j \text { se } k_{j-1} \leq y<k_{j} \text { para } 1 \leq y<J
$$

The limits, $k_{o}$ and $k_{j-1}$, are stimated with $k_{o}=-$ $\infty$ e $k_{j-1}=+\infty$, according to the model assumed.

There is, therefore, considering $\mathrm{j}$ categories:

$y_{1}=0$ if $k_{0}=-\infty \leq y_{i}^{*}<k_{1}$

$y_{1}=1$ if $k_{1} \leq y_{i}^{*}<k_{2}$

$$
y_{\mathrm{j}}=J \text { if } k_{j} \leq y_{i}^{*}=\infty
$$

Odds, interpreted with the marginal effects, result from a vector of explanatory variables, as can be seen in (4):

$$
\begin{aligned}
& \operatorname{Pr}(y=j \mid X)=\operatorname{Pr}\left(k_{j}-1 \leq y^{*}<k_{j} \mid X\right)= \\
& \mathrm{F}\left(k_{j}-X \beta\right)-\mathrm{F}\left(k_{j-1}-X \beta\right)
\end{aligned}
$$

Its important to say, that the ordered logit model in the traditional manner, presents the possibility of parallel lines, this is, the explanatory variables impacts statistically the same way along the $J$ categories (at this model is given the name of logit ordered pattern). However, Long \& Freese $^{14}$ and Cameron \& Trived $^{15}$ look to the fact that the stated hypothesis by the standard model can be violated in unusual situations, as health status of enquired elderly.

\begin{tabular}{lc}
\hline \multicolumn{1}{c}{ Reported Health Status } & Percentage \\
\hline Very Good & 2,96 \\
Good & 11,06 \\
Regular & 42,11 \\
Bad & 36,42 \\
Very Bad & 7,45 \\
Total & 100,00 \\
\hline
\end{tabular}

Source: Self elaboration after PNAD 2008 data.

Table 2. Description Statistics of explainable variables on family composition impact over the Brasilian elderly health self-report.

\begin{tabular}{lccc}
\hline \multicolumn{1}{c}{ Variables } & Average & Minimum & Maximum \\
\hline Age & 70,70 & 61 & 108 \\
Family income strip & 3,88 & 0 & 7 \\
Studying years & 4,90 & 0 & 16 \\
Psons - lives only with sons & 0,07 & 0 & 1 \\
Pdaughters - lives only with daughters & 0,06 & 0 & 1 \\
Pcff - lives with spouses and children & 0,07 & 0 & 1 \\
Conjsons - lives with spouses and sons & 0,13 & 0 & 1 \\
Conjdaughters - lives with spouses and daughters & 0,10 & 0 & 1 \\
Npcmff - don't have spouse but lives with children & 0,16 & 0 & 1 \\
Psc - Just lives with spouse, but no children & 0,30 & 0 & 1 \\
South & 0,15 & 0 & 1 \\
Northeast & 0,26 & 0 & 1 \\
Southwest & 0,46 & 0 & 1 \\
Midwest & 0,06 & 0 & 1 \\
Urban & 0,82 & 0 & 1 \\
Physical Mobility & 0,38 & 0 & 1 \\
Mobility affected by decease & 0,77 & 0 & 0 \\
Health plan & 0,28 & 0 & \\
\hline Soue: Sef & & & \\
\hline
\end{tabular}


some variables may impact statistically differently among different sorting options of the existing categories.

Therefore, in case the ordered pattern model is not the most appropriate, which is equivalent to the negation of the hypothesis is determined Hypothesis of Parallel regressions, they have two methodological possibilities, namely: Widespread ordinal model and the ordered model of odds partial proportional.

The basic difference between the three models is the possibility of statistically significant divergence of the estimated $\beta$ 's along the categories. Thus, the generalized model the assumption is that the estimated $\beta$ 's are different for all $J$ categories of the dependent variable. Moreover, the ordered pattern of partial proportional odds is an intermediate between the standard template and widespread. As the most suitable choice among the above three models is performed with the Brant test that indicated the model of partial proportional odds as the most appropriate ${ }^{15}$. The test statistical significancy provides evidences that the suposed parallel regression was violated. The test results can be found with the authors.

\section{Results}

As already stated, the key question of this work is the health status of the elderly. The interviewed are asked on the following question: "In general, consider their own health as ?" about this question, five options are displayed: (1) very good, (2) good, (3) regular, (4 ) bad and (5) very bad. Table 1 summarizes the frequency of the responses provided by the individuals surveyed. The sample has a total of 36457 people.

It is possible to see that the majority of interviewed stated that the general state of health is regular, this percentage is of $42,11 \%$. But the bad general condition was the second most stated, if added the fair and poor states, it sums up just over $78 \%$. This represents a relatively high percentage.

Regarding the demographic and socioeconomic characteristics of the interviewed, its possible to see that the average age is just over 70 years (remembering that a cut in the sample was done, only people over 60 years were considered). Towards the income, the majority of seniors have incomes between a half and a minimum wage. The majority of older people have low education, the average was 4,9 years, it means, on average, most have completed elementary school. The
Southeast and Northeast regions concentrate most of the elderly, respectively, $46 \%$ and $26 \%$. Much lives in urban areas, that percentage reaches $82 \%$.

About physical mobility, over $38 \%$ of seniors declare that they have some kind of handicap (to move around and/or perform minor tasks and/ or feeding themselves). As for morbidity from chronic diseases, $77 \%$ of seniors reports having at least some type of chronic disease. Colum or beck decease, rheumatism or arthritis, cancer, diabetics, bronchitis or asthma, hypertension, hart condition, renal chronic insufficiency, depression, tuberculosis, tendinitis and cirrhosis. Regarding health insurance, only $28 \%$ reports having some kind of private health insurance.

In order to test the hypothesis that co-residing relatives can improve self-perception of health of the elderly, the econometric exercise will be held for four distinct groups: i) men, women, aged between 60 and 69 years, and elderly with more than 70 .

Table 3 presents the results of econometric models of the logit ordered partial proportional odds, where a combination of spouse and children were used, besides adding a number of children in the household. Initiating research for the group of men, we found no evidence that self-reported health status is affected by the coexistence with only children, or sons and daughters or have only spouse and children. However, when the elderly has only spouse and children (male) the probability that the same have a better perception of his health is greater.

The results for the group of women presents considerable divergences from those found for the group of men. Initially, we noted that women who have sons have less tendency to believe that their health is very good and more likely to perceive their health as fair. In relation to those having only daughters, the results indicates that the lower the probability of perception is very good and good and the greater the odds of felt and reported health is fair, poor or very poor. With regard to groups of women that have both spouse and children, or only sons, or only daughters, the results point to a greater probability of better health perception for those who lives with relatives. Another result is that the presence of only the spouse increases the likelihood of perceived health being good or very good.

For all other controls used to model the perception that seniors have of their own health, its noted that better socioeconomic outcomes (higher levels of income, education and if pos- 


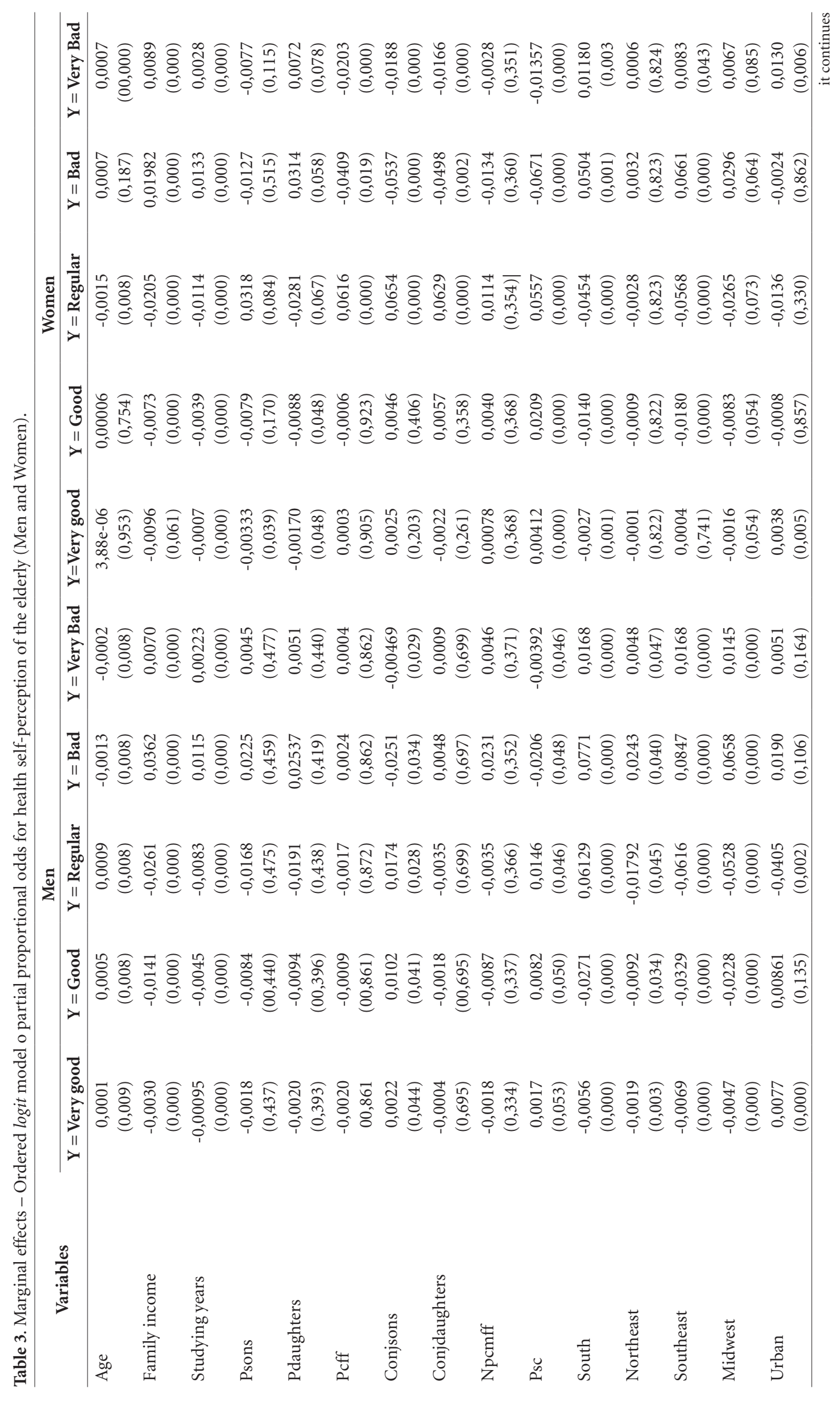


sesses health insurance) increases the likelihood that the person perceive their health as good or very good. On the other hand, as expected, having mobility problems or diagnosed diseases reduces the likelihood of believing that their health is good or very good, so much for men as for women.

The investigation of the impact of co-residence with children and spouses in the perception of health, dispersed by age group, illustrates that for individuals up to 69 years the fact of coexisting only with sons do not affect significantly the statistical perception of self-reported health . Furthermore, coexistence with daughters increases the probability for a better perception (specifically good or very good).

In addition, owning spouse, sons and daughters, or spouse and only daughters or spouse and sons, reduces the likelihood that an elderly of 69 years to report their health as poor or very poor. Furthermore, in accordance to the observed for the other groups, owning spouse (only with sons, or children or only daughters) increases the likelihood of the elderly judge their health as good or very good.

For seniors over 70 years, the results also points to a better health self-perception for elders who lives with children, or only sons, or only daughters and even to those living with spouse (Table 4).

\section{Discussion}

As previously reported, it was estimated four distinct models, presented in Tables 2 and 3, one dispersed by gender and another by age, given that, men and women experiences senility evolution, diseases and different qualities of life after 60 years age as well as the impact of living with family is divergent by gender.

Broadly, it is noted that the results indicates that living with children and owning spouse affects the perception that the elderly have of their health status, regardless of its real aspects of health and their socioeconomic status.

Initially, the possibilities set includes both the presence of only the spouse, or spouse and children (together and desagregatly only a son or just a daughter), so there is in the present study the individual socializing effect and the Interactive effect of family members in self-reported health. Specifically, it can be seen that there is a difference by gender in how the elderly perceives the role of the family in their welfare. The results 


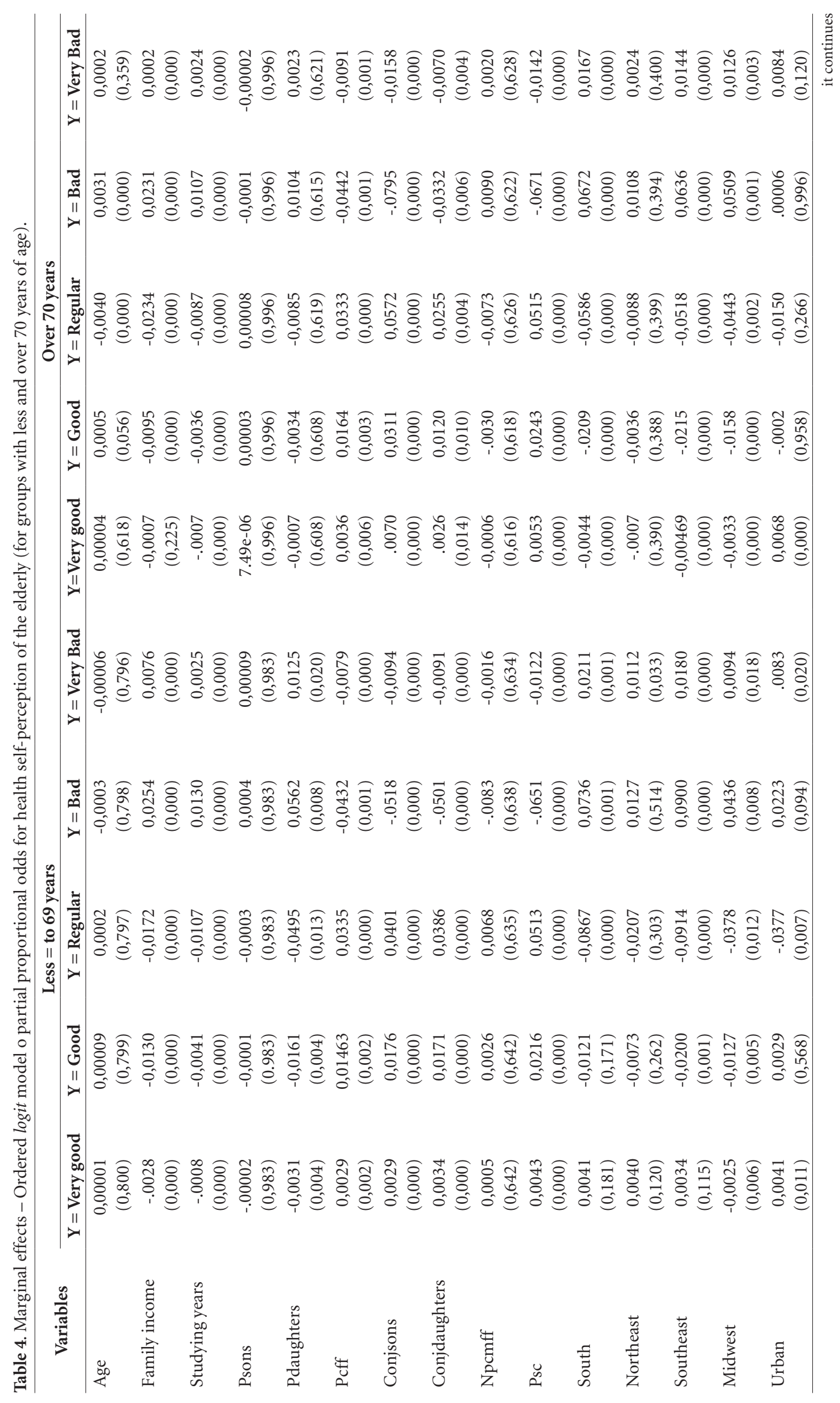


show that socializing with children significantly affects an optimal perception or the good health of women, while men showed sensitivity when socializing with their wives or sons.

The results also indicate, particularly for men having a wife and at least one male child improves the understanding that the elderly have of their own health. As for older women, self-perceived health as not bad or very bad health its inversely conditioned by having a husband, sons and daughters, being important therefore to life quality the individual or interactive presence.

Noteworthy also the impact of daughters in the wellness feeling that old women reported regarding their health. Estimations show that in Brazil the elderly women who socializes only with children are more likely to realize their health as bad or very bad. It should be noted that there is no consensus in the literature over the impact of the socializing role only daughters in the health awareness of women over 60 , however, Abreu et al. ${ }^{12}$ regards to a greater financial dependence that women have in the various tracks age, especially in old age. However, in the particular case of daughters dependency, also there is not a clear effect as noted by earlier research, some studies have found a positive effect, as found by Rahman ${ }^{8}$, others corroborates the results of the present study, since women still have a restriction on vis-a-vis men income, making them less financially available, besides the fact that married daughters, are relatively more available for their new families and therefore less available to the direct care of parents. Furthermore, in Brazil is still very frequent cases of grandparents who heads households and are sometimes responsible for the livelihood of daughters and grandchildren, which can, in this perspective, worsen their perception of health.

Corroborating these results the evidence found at Rahman and Menken ${ }^{16}$ points out that old age is no longer characterized by a phase in which the elderly need the financial care of others, since it is common that older people are in charge of families and supports them with their work or social security benefits . However, according to Marangoni and Oliveira ${ }^{17}$ and Camarano $^{18}$ the recent changes observed in the Brazilian economy led the elderly to assume a different role in the family and in society as a whole.

In addition to the arguments already mentioned, Abreu et al. ${ }^{12}$ highlights also another possible reason for increased dependence of women in relation to their daughters is that these are theoretically more reliable as direct caregivers than 
others, for example, a possible daughter-in-law. However, in this study, the data shows that the presence of only sons also reduces the likelihood that the woman notices his health as good or very good; finally, the main result observed for the group of women is that the presence of spouse is the main factor for a good (or very good) self-perception of their health status, regardless of the interactive effect with the children.

Regarding the results found for the group of men, the estimates indicate that the presence of a spouse and daughters, or the presence of only daughters, had no significant impact on their health self-reporting, these results are consistent with $^{3}$. On the other hand, men who only lives with their wives or wives and children are more likely to perceive their own health as good or very good. It is inferred in this case that the greater financial independence of older men towards women, reduces the relative dependence, such results are corroborated by Abreu et al. ${ }^{12}$ that found similar results for the people of Bangladesh.

\section{Final considerations}

This study aimed to measure the impacts of co-residence of sons, spouses and daughters on health's self-perceived among brazilian elderly. The main goal is that self-perception can have a diverse nature, both with gender specifications, as by age, assuming that people at older age 70 years old are comparatively more dependent than seniors at the beginning stage.

The breakdown by gender allowed to realize that men are just more sensitive to the presence and conviviality of their wives and sons. As for women, reports a better health regardless the gender of children with whom they live, if they have one child or more and relies heavily on the presence of the spouse. Draws attention however, the negative impact of socializing with her daughters in the well-being perception of the elderly, which is probably related to the increasing financial dependence of daughters from their mothers, much more likely to occur when compared to son's dependence.

No important differences were found between the results of groups of more and less than 70 years of age, however, note also that there is a perception of better health in both groups who lives with their spouses, sons and daughters. However, the impact of the spouse is more important to improve the sense of well-being, ranging health perception as good or very good.
It is inferred that the results of this study have important implications for the well-being of the elderly in the medium and long term given to both the reduction in the fertility rate as the increase in longevity observed since the 1960s.

It also highlights the important policy suggestions from the results of this study. Initially, the differential role of sons and daughters in self-reported health of older people contributes to the argument that are necessary over time, measures that improve the quality of life of both children as parents. It also suggests the improvement and dynamism of support groups for the elderly, arising from unfamiliar sources, which can reduce the dependence that elderly parents have on their children. In addition, other important policy implications passes through the care of the elderly in interactive participation of groups that contributes to an increased active participation in society.

One of the most important results is that older people living in the presence of their spouses perceives their health and/or welfare in a more positive way. It is inferred that this fact is related to the mostly female widowhood, since women - regardless of age clippings analyzed - lives longer than men. Confirms these data, the Datasus information (2015) in which they are informed that in the 1996-2013 period died 10,712,402 men and 7,838,855 women in Brazil (for the elderly figures were 389,246 for men and 379,092 for women). However, besides the gender or age of the elderly, the spouse plays an important role in good health perception, therefore, measures to improve the health and quality of life of older people tends to have a multiplier effect on health perception of spouse.

\section{Collaborations}

MS Cruz worked on research and review of analyzes and methods of the article; JA Araujo worked on the analysis of the article; AN Paixão worked on article research and discussion. 


\section{References}

1. Instituto Brasileiro de Geografia e Estatísica (IBGE). [Online]; 2000. [cited 2014 Nov 14]. Available from: https://www.ibge.gov.br

2. Instituto Brasileiro de Geografia e Estatísica (IBGE). Censo Demográfico. Rio de Janeiro: IBGE; 2010.

3. Alfieri F M, Teodori R M, Lima MI. Mobilidade Funcional de Idosos Submetidos a Intervenção Fisioterapêutica. Saúde em Revista 2004; 6(14):45-50.

4. Glaser K, Grundy E. Marital status and long-term illness in Great Britain. Journal of Marriage and the Family 1997; 59(1):156-164.

5. Arber S, Cooper H. Gender differences in health in later life the new paradox? Soc Sci Med 1999; 48(1):61-76.

6. Lilard LWL. Till death do us part: marital disruption and martality. American Journal of Sociology 1995; 100(5):1131-1156.

7. Kaplan GA, Salonen J, Cohen RD, Brand RJ, Syme L, Puska P. Social Connections and mortality from all causes and from cardiovascular diseare: prosppective evidence from Eastern Finland. Am J Epidemiol 1988; 128(2):370-380.

8. Rahman O. Age and gender variation in the impact of household structure on elderly mortality. Int J Epidemiol 1999; 28(3):485-491.

9. Rahman MO. The impact of co-resident spouces an sons on elderly mortality in rural Bangladesh. J Biosoc Sci 2000; 32(1):89-98.

10. Corrêa CS, Queiroz BL, Fazito D. Relação entre tamanho e estrutura da rede de apoio eo tempo individual dedicado à atenção ao idoso na cidade de São Paulo, 2000. Revista Brasileira de Estudos de População 2016; 33(1):75-97.

11. Su Y, Ferraro FK. Social Relations and Health Assessments Among Older People: Do the Effects of Integration And Social Contributions Vary Cross-Culturally? J Gerontol B Psychol Sci Soc Sci 1997; 52B(1):27-36.
12. Abreu M, Siqueira A, Cardoso CS, Caiaffa WT. Modelos de Regressão Logística ordinal: aplicação em estudo sobre qualidade de vida. Cad Saude Publica 2008; 24(Supl. 4):581-591.

13. Instituto Brasileiro de Geografia e Estatísica (IBGE). Pesquisa nacional de amostra por domicílio (PNAD 2008 - Suplemento de Saúde). Rio de Janeiro: IBGE; 2014.

14. Long J, Freese J. Regression Models for Categorical Dependent Variables Using Stata. $2^{\text {nd }}$ ed. College Station: Stata Press; 2006.

15. Cameron A, Trived P. Microeconometrics Cambridge: Cambridge University Press; 2005.

16. Rahman O, Menken J. The impact of family members on the selfreported health of older men and women in a rural area of Bangladesh. Ageing and Society 2004; 24(6):903-920.

17. Falcão DVS. A família e o idoso: Desafios da Contemporaneidade. Campinas: Papirus; 2010.

18. Camarano A. Envelhecimento da População Brasileira: Uma contribuição Demográfica. Rio de Janeiro: IPEA; 2002.

Artigo apresentado em 19/03/2016

Aprovado em 09/09/2016

Versão final apresentada em 11/09/2016 